\title{
EFFECTS OF CYCLIC SOLUTION TREATMENT ON THE MICROSTRUCTURES AND MECHANICAL PROPERTIES OF ALLOY 718
}

\author{
Jaekeun Hong ${ }^{1}$, Jihong Park ${ }^{1}$, Nhokwang Park ${ }^{1}$, Seongjun Kim² and Chungyun Kang ${ }^{2}$ \\ ${ }^{1}$ Korea Institute of Machinery \& Materials \\ 66 Sangnamdong, Changwon, Kyungnam 641-010, Korea \\ ${ }^{2}$ Dept. of Materials Engineering, College of Engineering, Pusan National University \\ 30 Jangjeondong, Geumjeong-gu, Busan 609-735, Korea
}

Keywords: Cyclic Solution Treatment, Low Cycle Fatigue, $\delta$-phases, Alloy 718

\begin{abstract}
Effects of solution treatment on the microstructure and mechanical properties in wrought Alloy 718 were investigated. For the improvement of tensile and fatigue properties of wrought Alloy 718 , a cyclic solution treatment, heating at $1000^{\circ} \mathrm{C}$ for 3 minutes followed by furnace cooling at the rate of $3^{\circ} \mathrm{C} /$ minute and holding at $985^{\circ} \mathrm{C}$ for 8 minutes, was proposed. The cyclic treatment was performed repeatedly 3 times and the samples were air-cooled to room temperature. After the cyclic solution heat treatment, Alloy 718 was subject to the standard aging treatment, holding at $718^{\circ} \mathrm{C}$ for 8 hours followed by cooling at the rate of $55^{\circ} \mathrm{C} /$ hour and holding at $620^{\circ} \mathrm{C}$ for 8 hours, and finally air cooled to room temperature. For the purpose of comparison, a standard heat treatment was also performed by solution treatment at $955^{\circ} \mathrm{C}$ followed by aging. The microstructures of the heat-treated samples were analyzed by optical microscopy and scanning electron microscope (SEM). Cyclic solution treatment resulted in the formation of small spherical shaped $\delta$-phases without grain growth. However, the $\delta$-phases of the standard heattreated specimen showed needle-like morphologies. Tensile and low cycle fatigue tests were performed on both cyclic heat-treated and standard heat-treated specimens at room temperature, $350^{\circ} \mathrm{C}$ and $650^{\circ} \mathrm{C}$. Low cycle fatigue tests on the cyclic treated specimens showed promising results without reduction of strength.
\end{abstract}

\section{Introduction}

Since the development of the Alloy 718 by Eiselstein in 1962, it has been widely used in gas turbines, aircraft engines, high temperature plants and nuclear fusion vessels. Alloy 718 has desirable properties which have resistance to fatigue, creep and oxidation combined with a high strength[1,2]. Because of these properties, Alloy 718 was widely used in the environments such as high temperature, under cyclic loads, and long periods. Therefore fatigue properties of Alloy 718 has been extensively studied especially for high temperatures[3 10]. Forging Alloy 718 was 
normally used at the temperature up to $650^{\circ} \mathrm{C}$. The reason for this limitation is the transition of principal strengthening phases $\left(\gamma^{\prime \prime} / \gamma^{\prime}\right)$ to $\delta$-phase with increasing thermal exposure temperatures and times. So, its mechanical properties were easily degraded at the temperature above $650^{\circ} \mathrm{C}$ $[11,12]$. When Alloy 718 was aging at the temperature above $870{ }^{\circ} \mathrm{C}$, the $\delta$-phase was precipitated with niddle-like or globular morphologies and it was observed primarily at grain boundaries[13].

The $\delta$-phase of plate-like or needle-like morphologies degrades the low cycle fatigue properties and low temperature fracture toughness. This degradation was due to $\delta$-phase as niobium-rich phase $\left(\mathrm{Ni}_{3} \mathrm{Nb}\right)$, and therefore elements $(\mathrm{Nb}, \mathrm{Ni})$ of matrix consequently should be depleted during precipitation. Since the chemical composition of $\gamma^{\prime \prime}$-phase(main hardening precipitate phase) is same as the composition of $\delta$-phase, it should be difficult to get proper hardening at the zone close to $\delta$-phase. Accordingly, mechanical properties of this zone should be degraded [14-18]. But, it was reported that $\delta$-phase of globular morphology was promising for fatigue properties[19-20]. A lot of studies were performed about heat treatment for enhancement of mechanical properties, however, many problems are still remaining about $\delta / \gamma^{\prime \prime} / \gamma^{\prime}$-phase control, grain size and precipitation free zone(PFZ)[21,22].

In this paper, modified solution heat treatment condition for globular $\delta$-phase precipitation were investigated without grain growth. The microstructures and mechanical properties were investigated both on standard heat treatment(SHT) and modified heat treatment specimens.

\section{Experimental procedure}

$\underline{\text { Materials }}$

The material used in this study was prepared from Inconel 718 bars $(\varphi 20 \mathrm{~mm})$ and the chemical compositions were given in Table 1 . The specimens were polished and etched with using marble reagent $\left(100 \mathrm{ml} \mathrm{HCl}, 100 \mathrm{ml} \mathrm{H}_{2} \mathrm{O}, 20 \mathrm{~g} \mathrm{CuSO}_{4}\right.$, a few drops of $\left.\mathrm{H}_{2} \mathrm{SO}_{4}\right)$. Optical microscope and scanning electron microscope (SEM) were used to analyze microstructures of raw materials and heat treated specimens. The raw materials were used as-rolled condition.

Table I. Chemical Composition of Alloy 718 Bar.

\begin{tabular}{|c|c|c|c|c|c|c|c|c|c|c|c|c|}
\hline Elements & $\mathrm{C}$ & $\mathrm{Mn}$ & $\mathrm{Si}$ & $\mathrm{Cr}$ & $\mathrm{Mo}$ & $\mathrm{Co}$ & $\mathrm{Ti}$ & $\mathrm{Al}$ & $\mathrm{B}$ & $\mathrm{Fe}$ & $\mathrm{Nb}$ & $\mathrm{Ni}$ \\
\hline wt.\% & 0.027 & 0.06 & 0.08 & 17.75 & 2.87 & 0.15 & 1.00 & 0.49 & 0.004 & 18.20 & 5.18 & Bal. \\
\hline
\end{tabular}

\section{$\underline{\text { Heat Treatments }}$}

The preliminary heat treatment test was performed to determine the condition of modified solution treatment condition below $\delta$-phase solvus temperature without grain growth. A cyclic solution heat treatment $(\mathrm{CHT})$, holding at $1000^{\circ} \mathrm{C}$ for 3 minutes followed by furnace cooling at the rate of $3^{\circ} \mathrm{C} /$ minute and holding at $985^{\circ} \mathrm{C}$ for 8 minutes, was proposed. The cyclic treatment was performed repeatedly 3 times and the samples were air-cooled to room temperature. After the cyclic solution heat treatment, Alloy 718 was subject to the standard aging treatment, holding 
at $718^{\circ} \mathrm{C}$ for 8 hours followed by cooling at the rate of $55^{\circ} \mathrm{C} /$ hour and holding at $620^{\circ} \mathrm{C}$ for 8 hours, and finally air cooled to room temperature. For the purpose of comparison, a standard heat treatment was performed by solution treatment at $955^{\circ} \mathrm{C}$ followed by aging. The cyclic solution heat treatment conditions were shown in Fig. 1.

\section{$\underline{\text { Mechanical Tests }}$}

Tensile tests were performed on raw materials, standard heat treatment and cyclic solution treatment specimens at room temperature and $650^{\circ} \mathrm{C}$. The values of tensile, yield strength and elongation were analized respectively. The low cycle fatigue tests were also performed on standard heat treatment and cyclic solution treatment specimens at room temperature, $350^{\circ} \mathrm{C}$ and $650^{\circ} \mathrm{C}$. The specimen geometries of low cycle fatigue test were shown in Fig. 2. The low cycle fatigue tests were carried out at three different maximum stress levels(800, 900 and $1000 \mathrm{MPa})$ with Instron-8516.

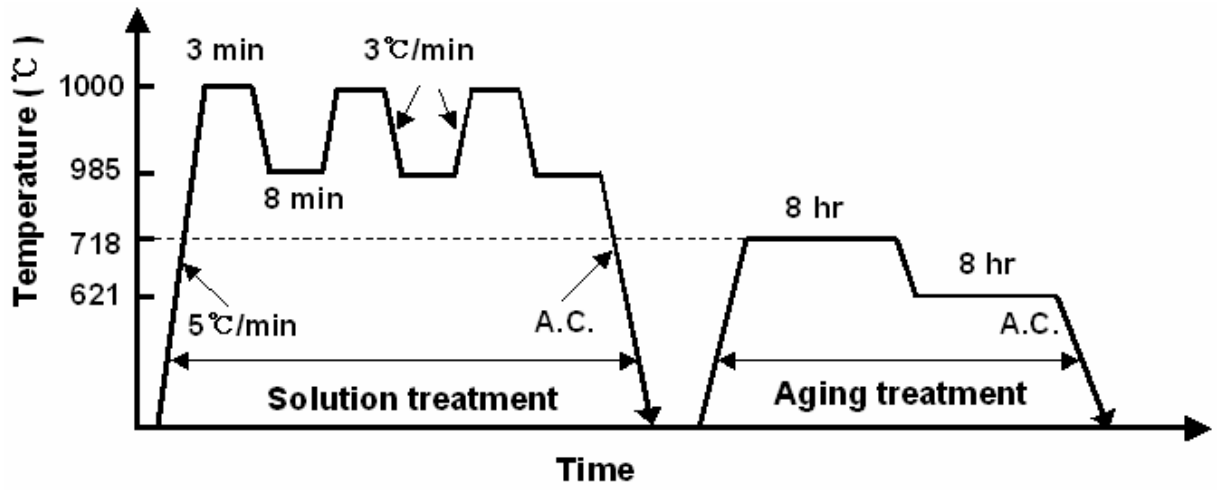

Fig. 1. Proposed cyclic heat treatment condition.

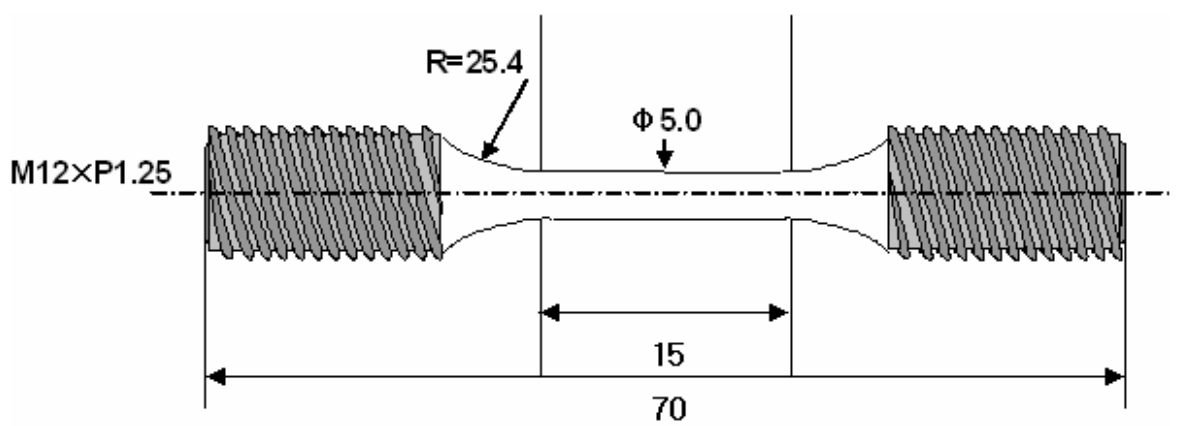

Fig. 2. Low cycle fatigue test specimen geometries. 


\section{Results and Discussions}

\section{Microstructures of raw material}

Prior to heat treatment, the microstructures of raw material were analyzed to confirm the grain size and initial conditions. The average grain size was $7 \sim 9 \mu \mathrm{m}$ and the primary carbides( $\mathrm{NbC}$, TiC) were randomly distributed with the size of $1 \sim 15 \mu \mathrm{m}$ as shown in Fig. 3.

\section{$\underline{\text { Heat treatments }}$}

The results of preliminary heat treatment test showed that grain growth was not formed at the conditions of $1000^{\circ} \mathrm{C}$ for 10 minutes and at $995^{\circ} \mathrm{C}$ for 1 hour. Fig. 4 showed that grain growth was rapidly formed at the condition above $1005^{\circ} \mathrm{C}$ for 1 hour. The abnormal grain growth is due to solution and shape of $\delta$-phases. The $\delta$-phases were almost solved, and the residual $\delta$-phases were small granular shapes at the condition of $1005^{\circ} \mathrm{C}$ for 1 hour as shown in Fig. 5. Therefore, it was very difficult to inhibit grain boundary from migrating. And, concludingly the appropriate temperatures of modified solution treatment were observed between $985^{\circ} \mathrm{C}$ and $1000^{\circ} \mathrm{C}$ as shown in Fig. 1. The duration of solution treatment was 1 hour same as standard solution treatment. Standard aging treatment was applied after solution treatment.

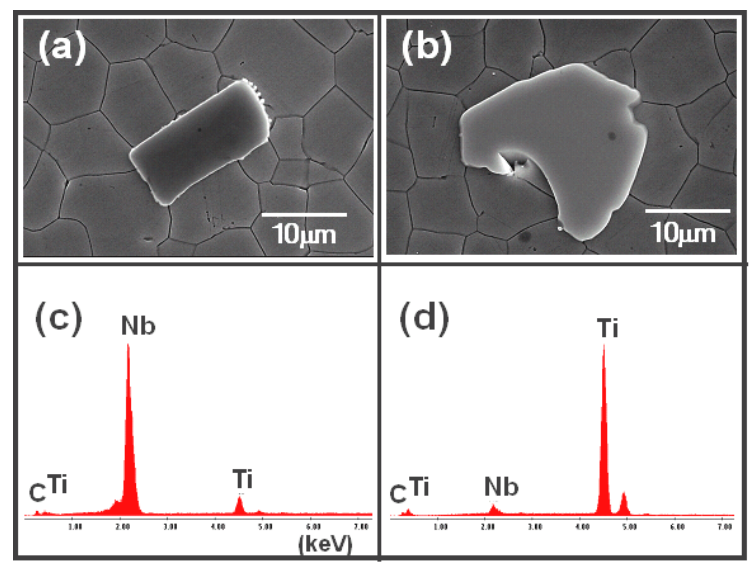

Fig. 3. SEM micrographs and EDS results of the as-polished Alloy 718 surface for : (a), (c) a Nb-rich carbide ; (b), (d) a Ti-rich carbide.

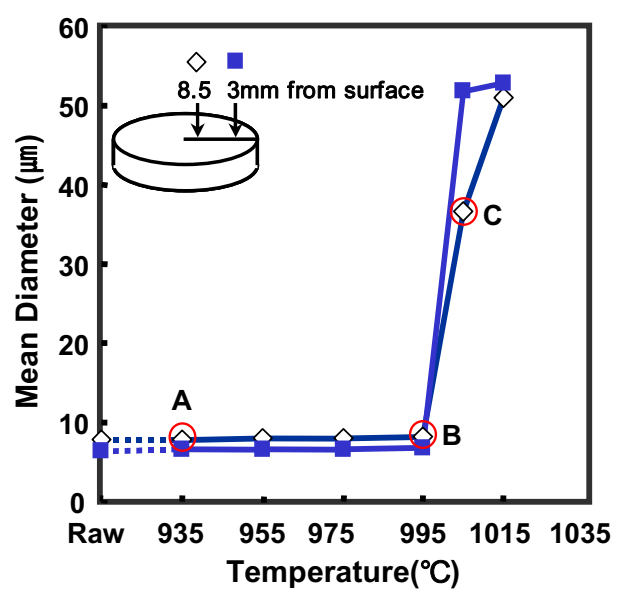

Fig. 4. Changes of grain size at annealing temperatures for $1 \mathrm{hr}$. 


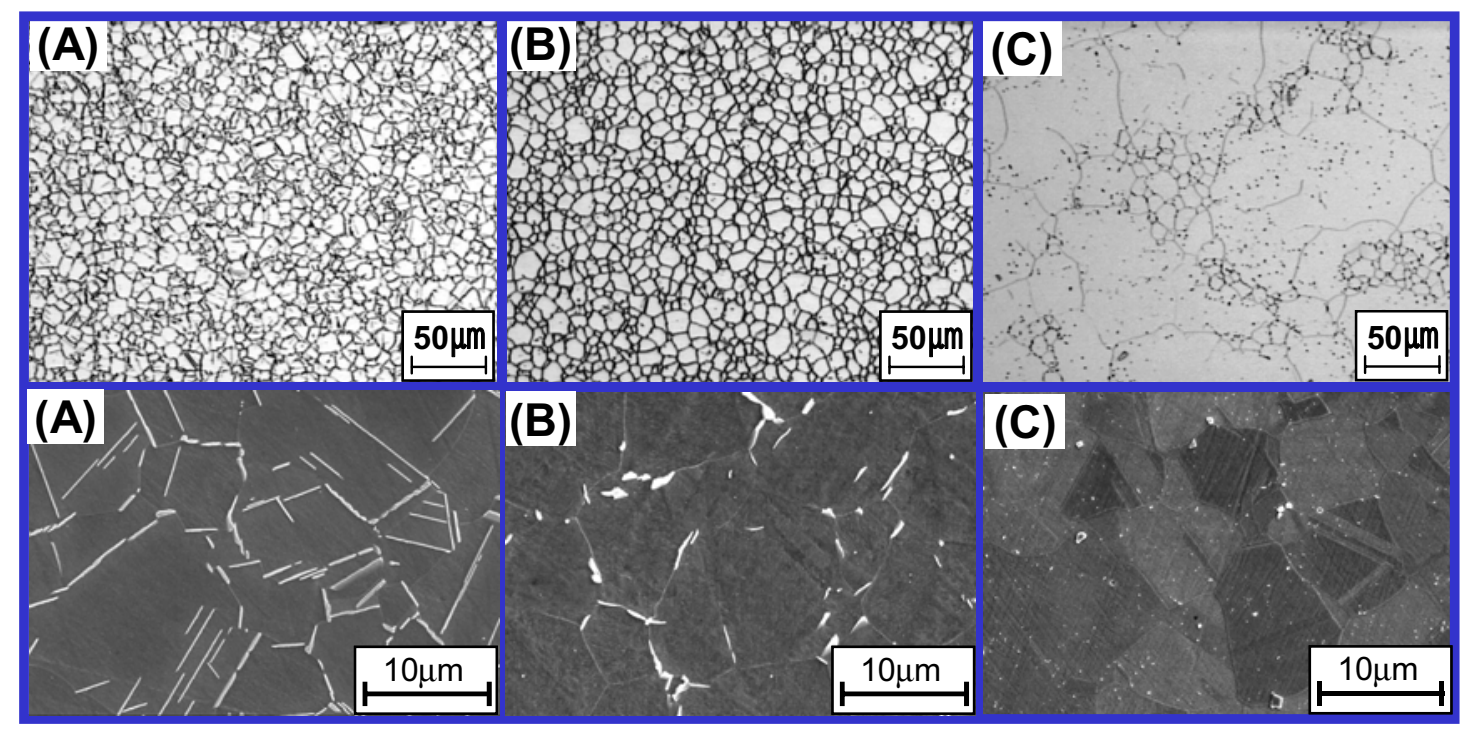

Fig. 5. Optical and SEM micrographs of solution heat treated specimens at : (A) $935^{\circ} \mathrm{C},(\mathrm{B}) 995^{\circ} \mathrm{C}$, (C) $1005^{\circ} \mathrm{C}$ for $1 \mathrm{hr}$.

The microstructures of SHT specimens showed that $\delta$-phases as needle-like morphology were precipitated along the grain boundaries, and the average grain size was $9 \sim 10 \mu \mathrm{m}$. However, cyclic heat treated specimens showed that small spherical shaped $\delta$-phases were precipitated without grain growth, and the amount of $\delta$-phases was small compared to that of SHT conditions. It was called "Controlled $\delta$-phases" after cyclic heat treatment.

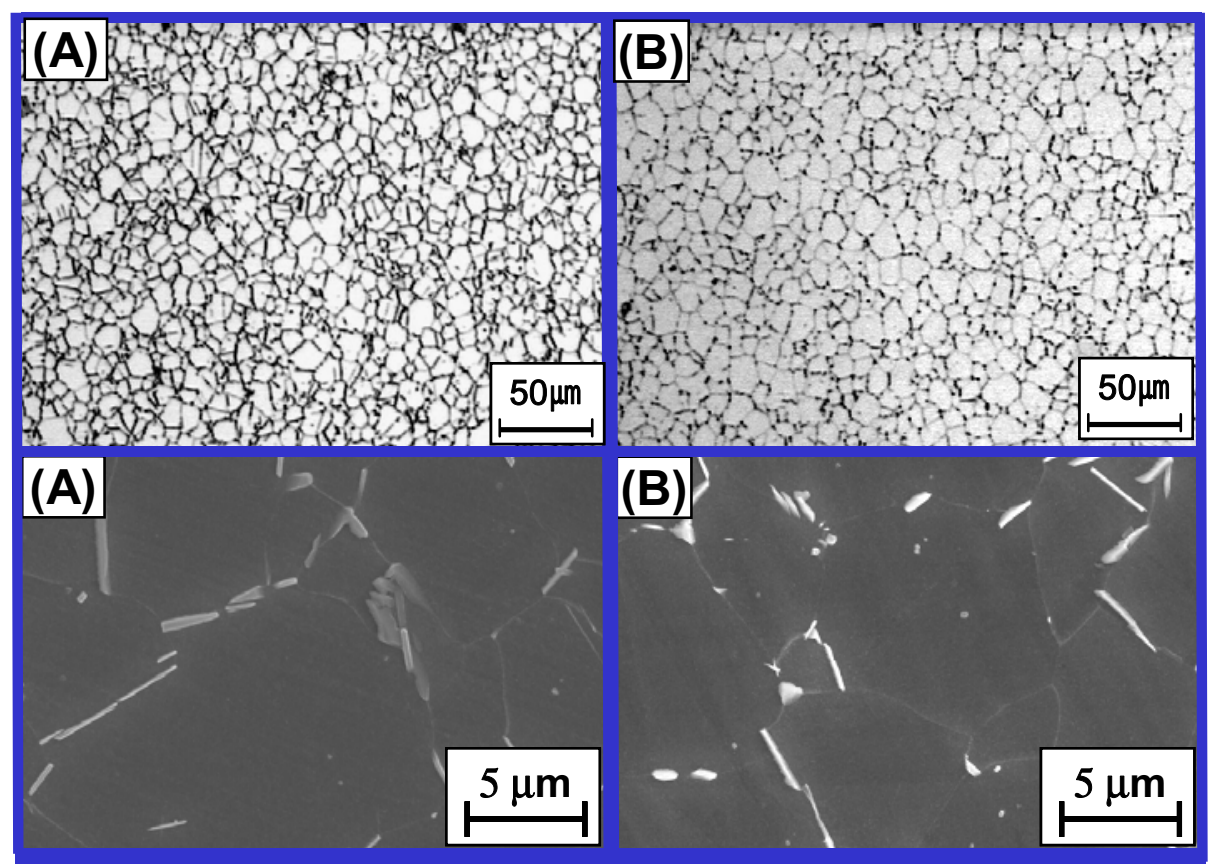

Fig. 6. Optical and SEM micrographs of SHT specimens(A) and Cyclic Heat Treatment specimens(B). 


\section{Effects of $\delta$-phases on Grain Growth}

To study the effects of $\delta$-phases on grain growth, Zener theory about interaction between a grain boundary and a second-phase inclusion was considered. According to the Zener theory, the restriction of grain growth is much more effective if the inclusion has finer shapes. The grain growth is described by equation (1).

$$
\mathrm{D}=\mathrm{k}(\mathrm{t})^{\mathrm{n}}, \log (\mathrm{D})=\mathrm{n} \cdot \log (\mathrm{t})+\log (\mathrm{k})
$$

(D : grain size, $\mathrm{k}$ : constant, $\mathrm{n}:$ grain growth exponent)

The high value of grain growth exponent(n) means high velocity of grain growth. Fig. 7 showed the variation of grain size and grain growth exponent at each solution temperature for 1 hour. The value of grain growth exponent was less than 0.03 and 0.1 at the temperature below $985^{\circ} \mathrm{C}$ at $1000^{\circ} \mathrm{C}$ respectively. This results means that the quantity of $\delta$-phases was reduced with increasing solution temperatures.

\section{$\underline{\text { Tensile Tests }}$}

The tensile properties of Alloy 718 were examined for 4 different heat treatment conditions such as as-rolled(AR), standard heat treatment(SHT), Merrick's heat treatment(MHT) and cyclic heat treatment(CHT) at the temperatures of RT and $650^{\circ} \mathrm{C}[21]$. The tensile strength of $\mathrm{CHT}$ specimens was slightly increased compared with those of SHT condition at the temperatures of RT and $650^{\circ} \mathrm{C}$. The yield strength and elongation of CHT specimens were nearly equal to those of SHT condition. This is due to the fact that the grain size was not increased after CHT. The tensile and yield strength of as-rolled specimens were improved after SHT, MHT and CHT, however elongation was decreased after heat treatments. The tensile properties of MHT specimens which formed grain growth were degraded compared with those of SHT and CHT specimens. The results of tensile tests were shown in Fig. 8.

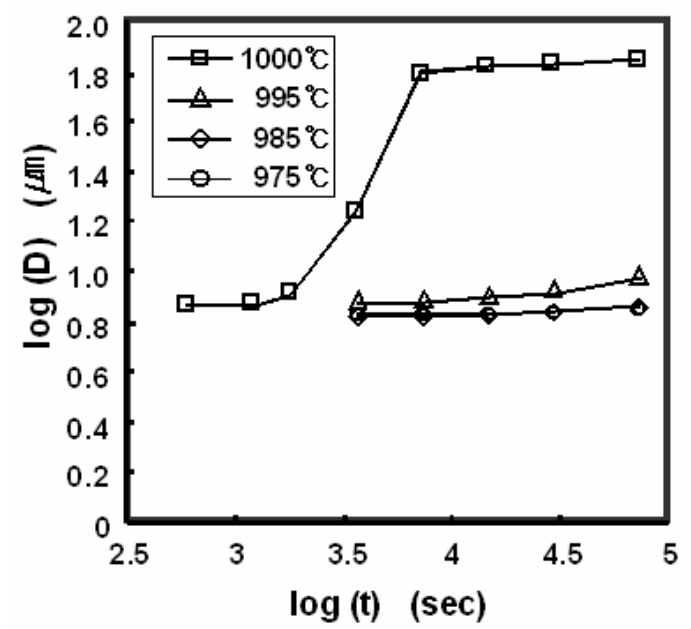

(a) Grain size variation

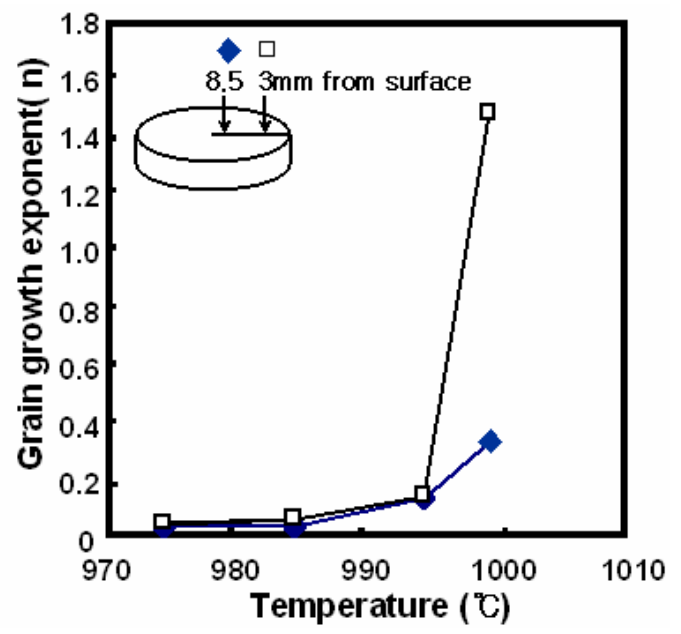

(b) Grain growth exponent

Fig. 7. Grain size variation and grain growth exponent(n) with increasing solution time and temperature. 


\section{$\underline{\text { Low Cycle Fatigue Tests }}$}

The low cycle fatigue tests were carried out at the temperatures of RT, $350^{\circ} \mathrm{C}$ and $650^{\circ} \mathrm{C}$ with a load ratio (R) of -1.0 and $1 \mathrm{~Hz}$ frequency (Maximum stress level : 800, 900 and $1000 \mathrm{MPa}$ ). The results of low cycle fatigue tests for SHT and CHT specimens were represented in Fig. 9.

In the case of maximum stress under $900 \mathrm{MPa}$, the fatigue lives of cyclic heat treated materials were improved compared with that of standard heat treated materials at RT. At the higher stress level such as $1000 \mathrm{MPa}$, fatigue lives of cyclic heat treated specimens were reduced compared with those of standard heat treated specimens as shown in Fig. 9 (a). It should be considered that the controlled $\delta$-phases of globular morphology after cyclic heat treatment helped the improvement of low cycle fatigue properties. When maximum stress over $900 \mathrm{MPa}$ was applied at the higher test temperatures such as $350^{\circ} \mathrm{C}$ and $650^{\circ} \mathrm{C}$, the fatigue lives of cyclic heat treated specimens were almost equal, or less than those of the standard heat treated specimens as shown in Fig. 9 (b). When maximum stress, $800 \mathrm{MPa}$ was applied, the fatigue lives of cyclic heat treated specimens were improved compared with those of standard heat treated specimens. The fatigue lives were rapidly decreased with increasing test temperature. The decreases of the fatigue lives were due to the increases of loaded stress/tensile strength ratios at high temperatures.

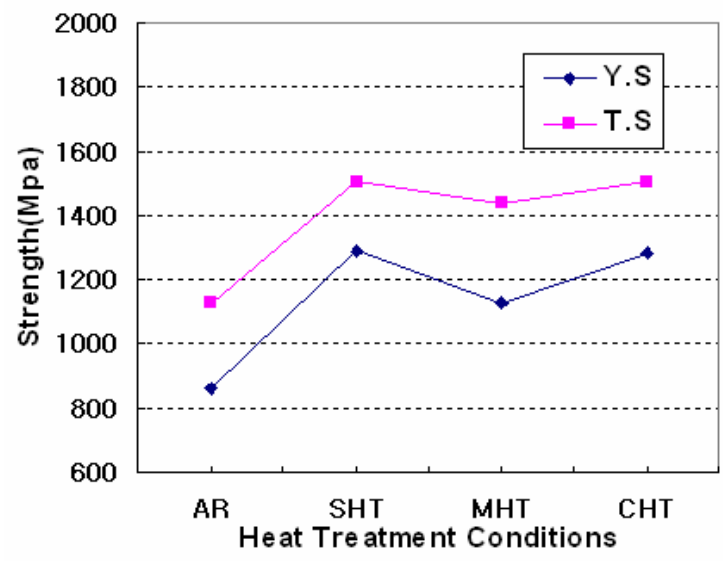

(a) at room temperature

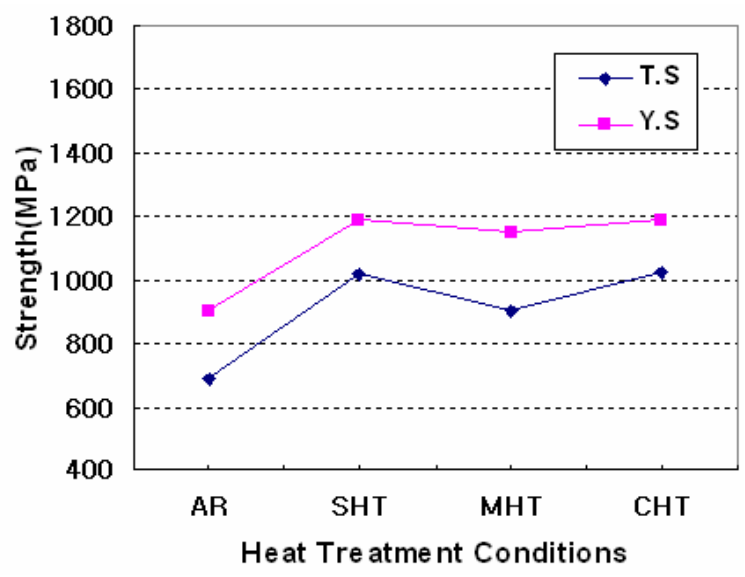

(b) at $650^{\circ} \mathrm{C}$

Fig. 8. Tensile properties of Alloy 718 for different heat treatment conditions. 


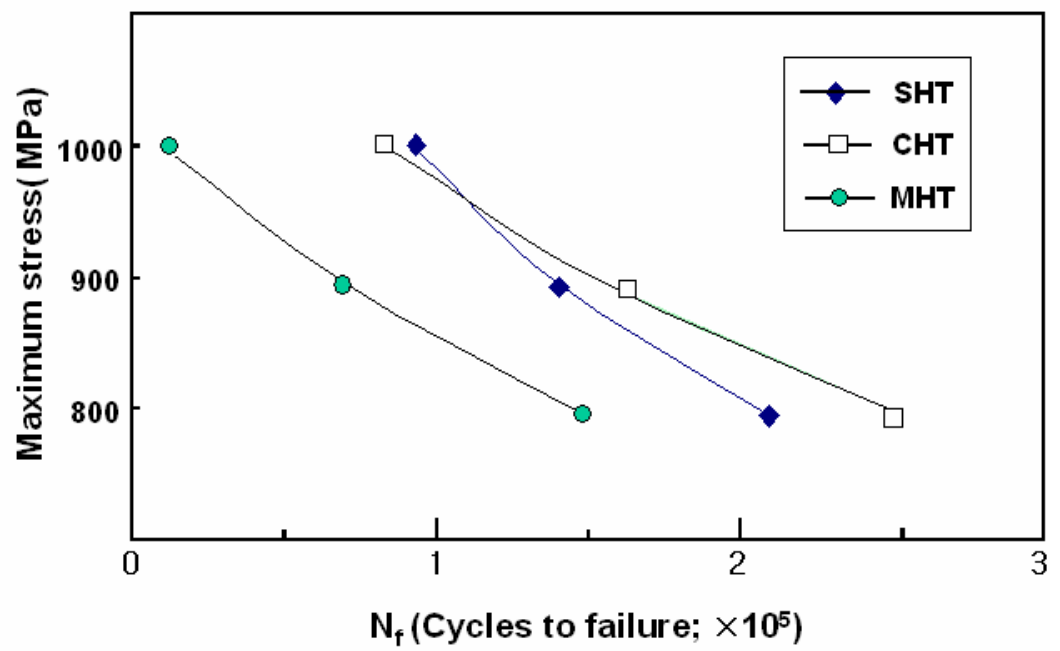

(a) at room temperature

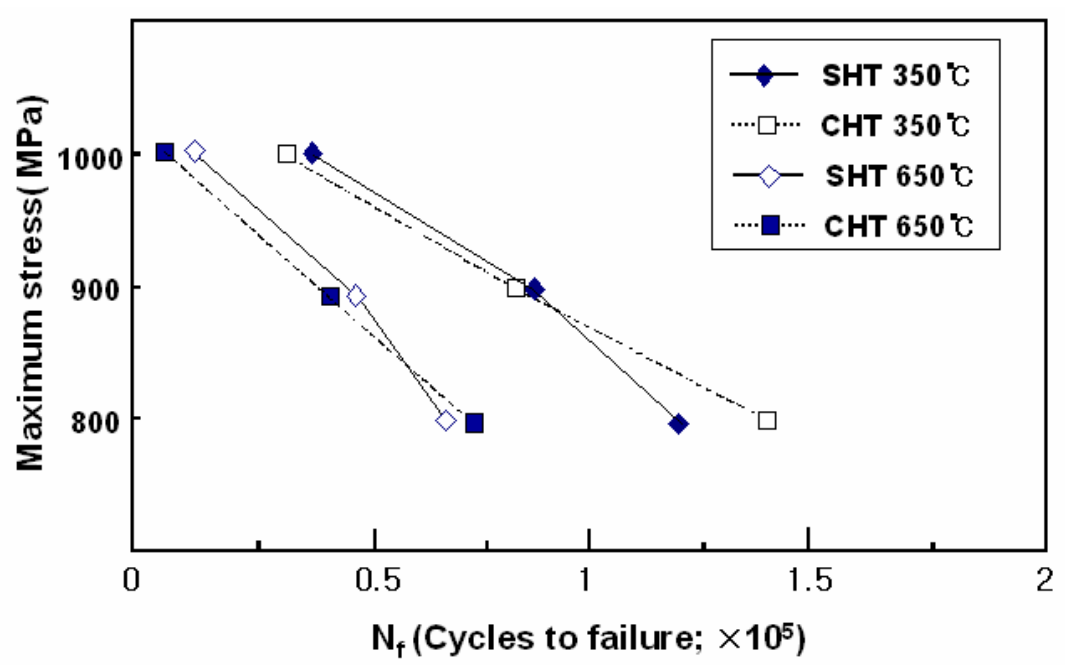

(b) at $350^{\circ} \mathrm{C}$ and $650^{\circ} \mathrm{C}$

Fig. 9. The results of low cycle fatigue test $(\mathrm{R}=-1, \mathrm{~F}=1 \mathrm{~Hz}$, Waveform $=$ Sine wave $)$.

\section{Conclusions}

- Grain growth of Alloy 718 was not formed at the condition of $1000^{\circ} \mathrm{C}$ for 10 minutes and $995^{\circ} \mathrm{C}$ for 1 hour. According to this result, modified solution heat treatment(cyclic heat treatment) was proposed to improve fatigue properties without grain growth and reduction of strength.

- The microstructures of cyclic solution treatment specimens showed that small globular and short needle shaped $\delta$-phases were precipitated without grain growth, and the amount of $\delta$ phases was smaller than that of standard heat treatment specimens. However, the $\delta$-phases of 
needle-like morphology were precipitated along the grain boundaries after standard heat treatment.

- The tensile properties of cyclic solution treated specimens was same as those of standard heat treated materials both at room temperature and $650^{\circ} \mathrm{C}$. This is due to the fact that grain growth did not form after cyclic solution treatment.

- At the room temperature and less than $900 \mathrm{MPa}$ stress level, the low cycle fatigue properties of cyclic solution treated specimens were improved compared with those of standard heat treated specimens. At the temperature of $650^{\circ} \mathrm{C}$ and less than $800 \mathrm{MPa}$ stress level, the low cycle fatigue properties of cyclic solution treated specimens were improved compared with those of standard heat treated specimens.

\section{Acknowledgement}

This research was supported by a Seed Grant from Dual Use Technology Project of the Ministry of Science and Technology (MOST) of Korea.

\section{References}

[1] E. A. Loria : J. of Metals, July (1988), p. 36

[2] T. Connolley, M.J. Starink and P.A.S. Reed : Proceeding of 9th International Symposium on Superalloys, TMS, (2000), p.435

[3] L. A. James : Proceeding of Superalloy 718 conference, TMS (1989), p. 499

[4] H. Ghonem, T. Nicholas and A. Pineau : Fatigue Fract. Eng. Mater. Struct., 16 (1993), p. 565

[5] M. Clavel and A. Pineau : Metall. Trans., A 9 (1978), p. 471

[6] J. P. Pedron and A. Pineau : Mater. Sci. \& Eng., 56 (1982), p. 143

[7] L. A. James : Eng. Fract. Mechanics, 25 (1986), p. 305

[8] S. Floreen and R. H. Kane : Fatigue Fract. Eng. Mater. Struct., 2 (1980), p. 401

[9] H. H. Smith and D. J. Michel : Metall. Trans., A 17 (1986), p. 370

[10] R. G. Andrews , A.K. Koul and P. Au : Proceeding of Superalloys 718,625 conference, TMS (1991), p. 943

[11] J. F. Radavich : Superalloys 718, 625, 706, TMS, (1997), p. 17

[12] F. Alexandre, S. Deyber and A. Pineau : Scripta Mater. 50 (2004), p. 25

[13] M. G. Burke and M. K. Miller : Proceeding of Superalloys 718,625 conference, TMS (1991), p. 337

[14] G. Sjoberg, N. G. Ingesten and R. G. Carlson : Proceeding of Superalloys 718,625 conference, TMS (1991), p. 603

[15] X. Xie, Z. Xu, B. Qu, G. Chen and J. F. Radavich : Superalloys 1988, The Metallurgical Society (1988), p. 505

[16] L. A. James and W. J. Mills : Engineering Fracture Mechanics, 22(1985), p. 797

[17] W. J. Mills and L. D. Blackburn : Journal of engineering Materials and Technology, 112(1990), p. 117

[18] D. D. Krueger : Proceeding of Superalloy 718, TMS (1989), p. 279

[19] C. T. Sims : Superalloys, TMS(1984), p. 399

[20] G. Q. Zhang, R. W. Zhang and M. G. Yan : ISTIC-Technical Report(TR-C000295), (1988)

[21] H. F. Merrick : Metall. Trans., 7A, (1976), p. 506

[22] A. K. Koul, P. Au, N. Bellinger, R. Thomburaj, W. Wallance and J. P. Immarrigeon : Proceeding of $6^{\text {th }}$ International Symposium on Superalloys, TMS (1988), p. 3 